\title{
A Study of Length Approach on L2 Vocabulary Learning
}

\author{
Hongying $\mathrm{Li}^{1} \& \mathrm{Li}$ Zhao ${ }^{2}$ \\ ${ }^{1}$ School of Foreign Languages, Jiangnan University, China \\ ${ }^{2}$ College of Arts, China University of Petroleum (East China), China \\ Correspondence: Hongying Li, School of Foreign Languages, Jiangnan University, China. E-mail: \\ marialee510@126.com
}

Received: January 30, 2015 Accepted: February 22, 2015 Online Published: May 31, 2015

doi:10.5539/ells.v5n2p39 URL: http://dx.doi.org/10.5539/ells.v5n2p39

\begin{abstract}
This research was conducted with a view to investigating the effects of Length Approach on L2 vocabulary learning. The study employed both a quantitative and a qualitative study, which yielded the following findings: with regard to college English vocabulary learning, learners' productive ability lags far behind their receptive ability. Learners' capability of using words in communication does not develop correspondingly with their vocabulary size. Learners tend to learn English words by means of studying the word list, which may be very dangerous, since what it displays is just pronunciation, word class, target-language equivalents, derivatives and occasionally one or two examples. Long composition writing task leads learners to become more aware of the new expressions or lexical phrases which can help enrich the content of their writing. The requirement of Length Approach is helpful to arouse learners' consciousness to accumulate new words and expressions and then use them in their writing. The data from the experiment provides supporting evidence to prove that exposure to meaningful comprehensible output practice enables learners to improve a lot in terms of language productive proficiency. The results demonstrate that Length Approach plays a positive role in building-up students' confidence, developing their initiatives, arousing their interest and motivating them to use more new words and expressions in writing practice, and enhancing their ability in English vocabulary learning. Length Approach, through awakening a producing desire and awareness in learners, promotes the transition from input to intake by timely practice of long composition writing.
\end{abstract}

Keywords: length approach, vocabulary learning, productive consciousness, productive competence

\section{Introduction}

Vocabulary is of crucial importance in second language learning and the bulk of learning a new language consists of learning new words (Vermeer, 1992; Gass \& Selinker, 1994; Wilkins, 1972). Vocabulary is indispensable when language function as a medium for communication (McCarthy 1990). As Candlin (1988) asserts, "The study of vocabulary is at the heart of language teaching in terms of organization of syllabus, the evaluation of learner performance, and the provision of learning resources". The acquisition of an adequate vocabulary is essential for successful second/foreign language use because, without an extensive vocabulary, it will be impossible for language learners to use the structures and functions they have learned for comprehensible communication (Rivers, 1983). Nation (1990) claims that both researchers and students think that vocabulary is extremely important and feel that inadequate, receptive and/or productive vocabulary is an obstacle in using a foreign language. Also, Levine and Reves (1990) note that, "Lack of adequate proficiency is often cited by English as a foreign language students as one of the obstacles to text comprehension."

There has long been an issue in our English teaching that few students can use English freely even though they have spent much time learning. Given this issue, Professor Wang Chuming et al.(2000) conducted a one-semester-long experiment on improving Chinese-speaking learners' English proficiency by means of writing long compositions. It indicates that writing long compositions will be conducive to the improvement of English proficiency.

Wang Chuming(2000) put forward "Length Approach". Its basic assumption is that through manipulation of the length requirement of writing, learners are pushed to write increasingly long compositions, which helps learners reinforce their sense of achievement, build up their confidence, motivate further learning and eventually transfer foreign language knowledge into foreign language proficiency. 
Length Approach has grabbed much attention of the foreign language world ever since it has been put forward. Many scholars confirm that Length Approach has a positive effect on L2 learning from the theoretical point of view. Zhong Shuneng (2004) analyzes the principles of Length Approach from the perspective of constructivism and concludes his article by claiming that the Length Approach in composition writing has brought about positive influence on foreign language teaching and learning, and it is also a down-to-earth instantiation of the constructivism-oriented design of teaching principles. He Ziran(2004) suggests a reverse thinking that guides and improves our FL teaching and learning. He holds that the teaching perception of "extensive writing training" is a reflection of the reverse thinking and shows his approval of the Length Approach. He believes that, guided by the reverse thinking, we are able to gain from multi-visual angles new understanding and new attempts at FL teaching and learning, thus making new contributions to the FL teaching reform in our country. Another expert, Qian Guanlian (2004) points out that the learners will recognize their boring means of expression in the process of writing a long text - the longer text they write, the more weaknesses they present. So, they want more and more useful and proper expressions, and may try more complex sentence structures, such as independent elements containing present participles or past participles, so as to make their writing perfect. By doing so, they become more confident. The more you write the more expressions you use. Moreover, Wu Fei (2005) investigates the relationship between comprehensible output and language learning efficiency based on theories of comprehensible output of second language acquisition and notions of the Length Approach. Findings of his study show that the implementation of the Length Approach can help enhance learners' writing skills and also improve English learning in general.

Wang Lifei (2004) has performed an experiment on writing long compositions out of class. The paper reports on a 20-week teaching for 83 sophomores of English major. He divides them into two groups: Group A and Group B, with different teaching methods respectively. Both Group A and Group B are taught by means of writing skills and writing exercises. In addition, Group B is required to write long compositions after class. As a result, Group B improves more conspicuously in diction and linguistic correctness than Group A. The experiment suggests that writing long compositions exerts positive influence on FL writing competence. That is to say, the Length Approach is feasible in teaching practice.

Fang Lingling (2004) reports that a one-year Length Approach writing instruction for 35 freshmen at Guangdong University of Technology. The results of her study suggest that, the processes of writing training not only play a positive role in actual writing performance, but also have a potential positive effect on language proficiency. Qin Xiubai (2004) points out that in the experiments of foreign language teaching, choosing "writing" as an entrance can grasp the philosophic significance in SLA, such as the relationship between language and mentality, as well as language and thinking.

In addition, Wang Chuming (2004) carries out an investigation into the effect of the Length Approach on vocabulary acquisition in EFL learning. In his experiment, 107 first-year English majors were required to read two passages inside class and learn the new words and expressions in them. They were then asked to write an English composition outside class. The experimental group was instructed to use as many as possible those words and expressions learned in class while the control group was not so required. The results showed that words used once in the composition were retained longer in memory, suggesting that requirements for language use in writing tasks could facilitate L2 learning. Wang Qi \& Deng Di (2012) attaches much importance upon culture in English writing and suggests that cultural exploration improves the Length Approach of writing.

However, few empirical researches so far have been carried out among non-English majors in terms of its effects on L2 vocabulary learning. The present study intends to investigate whether Length Approach is feasible among non-English majors, whether writing long compositions has a positive effect on the quality of vocabulary acquisition, especially on the improvement of the vocabulary productive ability of non-English majors, in the hope of seeking some pedagogical implications and insights for college English vocabulary teaching and learning.

\section{Methodology}

\subsection{Research Questions}

1) Does learners' productive competence of vocabulary develop correspondingly with their vocabulary size?

2) Is Length Approach helpful to raise learners' consciousness of using new words and expressions?

3) Is Length Approach an effective means to foster learners' productive competence in L2 vocabulary learning?

4) Does Length Approach play a positive role in enhancing learners' comprehensive English proficiency in the process of second language acquisition? 


\subsection{Participants}

The participants for the study are selected from first-year undergraduates of non-English majors in China University of Petroleum. According to their test scores of the final examination in the first term, one hundred and ten students in four intact classes taught by the same teacher, one of the researcher's colleagues, are selected as participants. Two classes from Geo-resources and Information major are chosen to be experimental group (EG), and the other two from Petroleum Engineering major as control group (CG). Their age ranges from 17 to 22, with an average of 19.49. They have been learning English for 6-8 years, with an average English-learning length of 6.54 years. All the participants are required to attend more than one test during the whole process of the experiment which lasts more than three months. It is unavoidable that some of them are absent from a certain test. Besides, some students fail to hand in their writing tasks occasionally. Therefore, the number of those who participates in all the required tests and those who have managed to hand in their writing assignments punctually is considered as the number of the participants whose test scores are counted in and analyzed in the experiment. A detailed description of the sample is reported in the following tables.

Table 1. Information of the participants

\begin{tabular}{lll}
\hline Category & Description & \\
\hline Group & Experimental Group (EG) & Control Group (CG) \\
Number & 56 & 54 \\
Major & Geo-resources and Information & Petroleum Engineering \\
Male/Female Ratio & $44 / 12$ & $42 / 12$ \\
Age Range & $17-22$ & $18-21$ \\
Age Average & 19.36 & 19.62 \\
English Learning & $6-8$ years & $6-8$ years \\
Experience & & \\
\hline
\end{tabular}

Table 2. Test scores of the participants

\begin{tabular}{llllll}
\hline Group & Number & Mean & Std. Deviation & T-value & Sig.(2-tailed) \\
\hline EG & 56 & 67.4821 & 10.56537 & \multirow{2}{*}{1.711} & .090 \\
CG & 54 & 63.8426 & 11.68567 & & $\mathrm{P}>0.05$ \\
\hline
\end{tabular}

Note. Std. Deviation means Standard Deviation; T-value means Test value; Sig. means Significance.

Table 2 tells that in the final examination of the first term, the performance of the participants reveals no obvious differences as to their English proficiency $(\mathrm{P}>0.05)$. It indicates that they are in roughly the same English proficiency. Therefore, we can conclude that these participants are relatively representative.

They participate in this study during the second term of their first year study, from March, to the end of June, 2007. They are chosen to take part in the experiment in the second term because that they have had one semester's college English education experience and thus have learnt some new vocabularies which provide convenience for the researcher to carry on the experiment. And the first-year undergraduates are selected because they have less pressure on passing CET 4 and they are expected to be more cooperative compared with the sophomores.

\subsection{Instruments}

In this study, three instruments, namely, tests, questionnaire and interview, are employed to collect and elicit information aiming at investigating the effects of Length Approach on L2 vocabulary learning.

\subsubsection{Tests}

(1) Pretest

A pretest (See Appendix I) is adopted before the writing task, which serves to work out whether the experimental group and the control group are of the same level in terms of both vocabulary size and productive competence. And also the pretest is used to investigate whether learners' productive competence of vocabulary develops correspondingly with their vocabulary size. The pretest is administrated at the very beginning of the second term of their first year study. All the words chosen in the test come from the words list of their textbook which they have learnt during the first term. And meanwhile the target words for testing productive competence are also 
among the Active Word List of College English Curriculum Requirements (for Trial Implementation). The result of it is used to compare with that of the posttest.

The pretest consists of two parts. The first part is composed of 60 multiple choice items. There are four choices after one English word whose meaning is presented in the form of Chinese equivalents. The participants are required to choose the correct meaning for each word. The examinee is given one point for each correct answer. The total score is 60. Part two is a VKS (Vocabulary Knowledge Scale) test, originally developed by Wesche and Paribakht(1994), to distinguish stages in learners' developing knowledge of particular words. Participants are presented with a target word in written form and required to indicate their self-perceived knowledge of the item in question by completing one or more of five self-report categories. These range from total unfamiliarity with the word, to knowledge of how to use it in grammatically and semantically correct ways in a sentence. If the participant either thinks or is sure he/she knows the meaning of the word he/she is required to demonstrate this knowledge by providing a translation, a synonym or its related collocation, or providing an appropriate sentence. The original form is shown as follows:

The target word (e.g.: delay)

I : I don't remember having seen this word before;

II : I have seen this word before but I don't know what it means;

III: I have seen this word before and I think it means_____ (synonym or translation);

IV: I know this word. It means (synonym or translation);

$\mathrm{V}: \mathrm{I}$ can use this word in a sentence, e.g.: . (If you do this section, please also do section IV).

The basic idea of the scale is to measure progressive degrees of word knowledge. Level I is not really a level at all, but reflects what the subject does not know. Levels II, III and IV are a measure of recognition vocabulary and Level $\mathrm{V}$ is a measure of productive vocabulary.

The author of this thesis modifies these confusing five scales into three. The revised one is as follows (See Appendix I ):

\section{I : I don't know this word;}

II : I know this word. It means (synonym or translation);

III: I can use this word in a sentence, e.g.:

There are 30 target words presented in this section. In the Vocabulary Knowledge Scale Test, participants will get zero if they mark "I don't know this word"; and one point for a correct answer in scale II. In scale three, two points, at best, will be awarded for a sentence that is correct in grammar and structure. It varies according to the degree of acceptance. The total score for this part is 60 points as well.

(2) Posttest

A posttest (See Appendix II) is designed to help figure out whether learners' productive competence will be improved after about four-month's experiment on Length Approach. Both the control group and the experimental group attend the posttest. The posttest is also intended to find out whether there will be any significant difference between the two groups in terms of their vocabulary productive performance.

As to the posttest, there is only the Vocabulary Knowledge Scale Test section, including 20 words and 10 phrases. For the posttest, the same scoring method is employed as in the pretest. And the target words are those they have learnt during the first year study and also among the Active Word List of College English Curriculum Requirements (for Trial Implementation). The total score is 60.

\subsubsection{Questionnaire}

A post-writing questionnaire (See Appendix III) is designed to collect some personal data on the effects of Length Approach. The questionnaire is made up of 14 items, each of which is answered on a 5-point scale, ranging from "I strongly disagree with this statement" to "I strongly agree with this statement". To be specific, the number " 1 " stands for "I strongly disagree with this statement", while the number " 5 " stands for "I strongly agree with this statement", with number"4", "3", and "2" stand for different degree of agreement respectively. The value 3 is regarded as the dividing line. That is to say, if the mean is below 3 , it indicates that the participants' attitude towards the item is negative; otherwise, their attitude is positive. The participants are required to read each item carefully, and then mark the number which can best represent their attitudes. The 
questionnaire is written in Chinese so as to avoid confusion and miscomprehension. And it is administrated after the written task and the posttest of vocabulary.

\subsubsection{Interview}

The instrument involved in the qualitative part is interviews with 6 students chosen randomly from among the participants of the experimental group. The interview is carried out at the end of the experiment to gather further information about the effects of Length Approach on L2 vocabulary learning.

The interview involves the following questions:

1) What kind of method did you adopt with regard to English vocabulary learning before? Was it effective?

2) What was the biggest problem you met in English vocabulary learning?

3) Is Length Approach helpful to solve these problems? Why (or why not)?

4) Can Length Approach help you enhance your vocabulary ability?

All the questions are asked in Chinese and the participants are told to feel free to answer the questions. During the process of the interview, the researcher listens carefully and asks more questions on any interesting and meaningful detail worth exploring rather than confined to the pre-designed ones. The interviews are recorded in a digital voice recorder and the content is later transcribed by the researcher.

\subsection{Procedures}

The whole experiment covers a span of more than 15 weeks from March to June in 2007. And it follows the following procedures:

1) According to the test results of National College Entrance Examination and the final examination of the first semester, students from four intact classes are chosen as participants. Two classes of one major are regarded as the experimental group, and the other two as control group.

2) At the very beginning of the experiment, a pretest of vocabulary is conducted among these two groups to collect information of their current vocabulary size and productive competence. All the participants are required to take it seriously and finish it within about fifty minutes.

3) A new English learning method - Length Approach is introduced to the experimental group. And then all the members of this group are required to write long compositions following the researcher's guidance and requirements. Based on the teaching ideas of Length Approach, the researcher designs the following topics for the participants to write on (See Table 3).

Table 3. Writing topics for the experimental group

\begin{tabular}{ll}
\hline Number & Topics \\
\hline 1 & I Have a Dream \\
2 & Why I Came to College \\
3 & If I Had Only Three Days to Live \\
4 & My View on... (Campus Love, Examination, Success, etc.) \\
5 & If a World Lacks... (Emotion, Money, Memory, Human Being, etc.) \\
6 & Pursuit of ... (Happiness, Health, Perfection, Wealth, etc.) \\
7 & Reflection on ... \\
8 & Who is Superior in College, the Boy or the Girl? \\
9 & A Current Problem with Youth (such as Internet Addiction...) \\
10 & Continuation of... \\
\hline
\end{tabular}

The participants are encouraged to express their ideas in a relaxing way, without being afraid of making errors. And they need not take the overall structure into consideration. The participants are asked to write without words limit but "the longer the better" and encouraged to write increasingly longer gradually.

4) The researcher evaluates the writing assignments in terms of 4 criteria, namely, length, language (here refers to the new words and expressions used in their writing), content and the neatness of the writing, with the length and language receiving the heaviest weighting. To be specific, length weights $40 \%$, language $30 \%$, content $20 \%$, and $10 \%$ for neatness. The participants are instructed to be sensitive to the active words of high frequency and beautiful expressions and strive to apply them in the writing after a thorough understanding of them. Considering 
their heavy burden, the researcher asks them to finish one writing task within 7-10 days. All the participants are required to hand in their writing punctually. The researcher puts emphasis on appreciating the elegant expressions rather than correcting the errors. As to the wonderful expressions, the researcher underlines them using a curve so as to make learners have a sense of satisfaction and achievement. And whenever there is an excellent writing, the researcher will analyze and appreciate it with them together.

5) At the same time, the control group is required to write on the same topics as the experimental group, but with word-limit of 120 words as usual. No information about Length Approach is mentioned to the control group. A majority of the participants in this group are inclined to adopt the "three paragraphs" pattern. The compositions of this group are scored in the traditional way.

6) Following all the writing tasks, the posttest concerning vocabulary productive competence is administrated among both the experimental group and the control group. The purpose of this test is to check whether there were any differences in vocabulary ability between the two groups after more than three months' experience of different writing methods. The posttest is finished within thirty minutes or so.

7) The questionnaire is distributed among the experimental group to get in-depth information three days after the posttest. The questionnaire is finished within 15 minutes and is collected on the spot.

8) A few days later, interviews are carried out after class in an informal way on a different day. The interviewees express themselves in quite a relaxing and pleasant atmosphere. Chinese is employed to achieve accurate and thorough understanding during all the process of interview. And the whole process of interview is recorded and transcribed by the researcher later.

9) Data and information get from the tests, questionnaire and interview are collected and analyzed with the help of SPSS 14.0.

\subsection{Data Collection and Analysis}

The following part presents and analyzes the results collected in the study, including the data from the pretest and the posttest, the test results of the final examination in the second term, and the information from the questionnaire and interview as well. With the help of the computer software analysis SPSS 14.0, the data collected are analyzed in terms of numbers, means (M), standard deviations (SD), and T-test. In the SPSS analysis, the confidence value is put at $95 \%$, which means, if $\mathrm{P}<0.05$, it is statistically significant.

Aiming at addressing the research questions, the following main comparisons are made and analyzed, namely, (1) comparison of the results from the pretest between the two groups; (2) comparisons of the results from the pretest and the posttest of the Experimental Group; (3) comparisons of the results from the pretest and the posttest of the Control Group; (4) comparisons of the results of the posttest between the two groups; (5) comparisons of the results from the final examination of the second term between the two groups.

\section{Results and Discussion}

\subsection{Results from the Pretest}

The data collected from the pretest is first analyzed, and a comparison is made between the experimental group and the control group in order to testify whether the two groups are at roughly the same proficiency level, to ensure the validity and reliability of the experimental results. The following tables will report the results of the pretest of the two groups specifically in terms of mean (M), standard deviation (SD) and T-value (T).

Table 4. Comparison of the data from the first part of the pretest between the two groups

\begin{tabular}{llllll}
\hline Group & $\mathrm{N}$ & $\mathrm{M}$ & $\mathrm{SD}$ & $\mathrm{T}$ & Sig.(2-tailed) \\
\hline EG & 56 & 51.0893 & 3.67437 & \multirow{2}{*}{1.324} & .188 \\
CG & 54 & 50.1111 & 4.05466 & & $\mathrm{P}>0.05$ \\
\hline
\end{tabular}

Note. $\mathrm{N}$ refers to the number of the participants.

Table 5. Comparison of the data from the second part of the pretest between the two groups

\begin{tabular}{llllll}
\hline Group & $\mathrm{N}$ & $\mathrm{M}$ & $\mathrm{SD}$ & $\mathrm{T}$ & Sig. (2-tailed) \\
\hline EG & 56 & 31.7321 & 5.55138 & \multirow{2}{*}{.780} & .437 \\
CG & 54 & 30.9259 & 5.28741 & & $\mathrm{P}>0.05$ \\
\hline
\end{tabular}

Note. $\mathrm{N}$ refers to the number of the participants. 
Table 6. Comparison of the data from the pretest as a whole between the two groups

\begin{tabular}{llllll}
\hline Group & $\mathrm{N}$ & $\mathrm{M}$ & $\mathrm{SD}$ & $\mathrm{T}$ & Sig. (2-tailed) \\
\hline EG & 56 & 82.8214 & 6.86521 & \multirow{2}{*}{1.440} & .153 \\
CG & 54 & 81.0370 & 6.11822 & & $\mathrm{P}>0.05$ \\
\hline
\end{tabular}

Note. $\mathrm{N}$ refers to the number of the participants.

The figures in Table 4 and Table 5 show that, the participants of the experimental group and the control group are at roughly the same proficiency level in terms of both their vocabulary size and their productive competence before the experiment. Firstly, the means of the EG and CG are very close. In part one $\mathrm{m}=51.0893$ for EG; and $\mathrm{m}=50.1111$ for $\mathrm{CG}$; in part two $\mathrm{m}=31.7321$ for $\mathrm{EG}$; and $\mathrm{m}=30.9259$ for CG. Besides, Std. Deviation of the EG and that of the CG of the two parts are also all but equivalent. In a word, $\mathrm{P}>0.05$, there is no significant difference between the two groups in terms of both the vocabulary size and the productive ability of the participants before the experiment, which guarantees the validity of the experiment to a great extent. As is presented in Table 4.6, there are no significant differences between the means of the pretest as a whole.

Table 7. Comparison of the results from the first part and the second part of the pretest for the EG

\begin{tabular}{lll}
\hline Test & Pretest & \\
\hline Part & 1 & 2 \\
Number & 56 & 56 \\
Mean & 51.0893 & 31.7321 \\
Std. Deviation & 3.67437 & 5.55138 \\
T & 22.484 & \\
Sig.(2-tailed) & .000 & \\
& $\mathrm{P}<0.05$ & \\
\hline
\end{tabular}

Table 8. Comparison of the results in the first part and the second part of the pretest for the CG

\begin{tabular}{lll}
\hline Test & Pretest & \\
\hline Part & 1 & 2 \\
Number & 54 & 54 \\
Mean & 50.1111 & 30.9259 \\
Std. Deviation & 4.05466 & 5.28741 \\
$\mathrm{~T}$ & 19.672 & \\
Sig.(2-tailed) & .000 & \\
& $\mathrm{P}<0.05$ & \\
\hline
\end{tabular}

The figures in Table 7 and Table 8 show that among both the experimental group and the control group, there are significant differences between participants' vocabulary size and their productive competence of vocabulary. Firstly, for the experimental group, $\mathrm{m}=51.0893$ in part one while $\mathrm{m}=31.7321$ in the second part; and for the control group, $\mathrm{m}=50.1111$ in part one and $\mathrm{m}=30.9259$ in part two. All these figures indicate that there is a very significant difference in their performance in part one and part two of the pretest. In addition, the T-test $(\mathrm{P}<0.05)$ also reveals the differences. It demonstrates that learners' productive competence lags far behind their vocabulary size, which indicates that learners' productive competence does not develop correspondingly with the vocabulary size. Therefore, it provides evidence to answer the first research question.

\subsection{Results from the Posttest}

Table 9. Comparison of the results from the posttest between the two groups

\begin{tabular}{llllll}
\hline Group & $\mathrm{N}$ & $\mathrm{M}$ & $\mathrm{SD}$ & $\mathrm{T}$ & Sig.(2-tailed) \\
\hline EG & 56 & 44.5714 & 5.63385 & \multirow{2}{*}{12.954} & .000 \\
CG & 54 & 31.6481 & 4.81020 & & $\mathrm{P}<0.05$ \\
\hline
\end{tabular}

Note. $\mathrm{N}$ refers to the number of the participants. 
Table 9 reports that, in the posttest, the experimental group and the control group are quite different in the means, (Experimental Group is 44.5714, while Control Group is 31.6481), and the difference is statistically significant $(\mathrm{t}=12.954, \mathrm{P}<0.05)$. This means that, the participants of the experimental group have made great progresses in their productive competence of vocabulary after about one semester's experiment on Length Approach. On the contrary, in the control group, the participants' performance in using new words still remains unsatisfactory. Furthermore, the differences can also be represented clearly by the figures in the following two tables, namely, Table 10 and Table 11. Figures in Table 10 demonstrate that, for the experimental group, the mean is 31.7321 in the pretest, while the mean is 44.5714 in the posttest, with $\mathrm{t}=-12.275(\mathrm{P}<0.05)$, which means there are significant differences in their performances in the two tests. While as for the control group, Table 11 indicates there is no obvious difference between the means of the two tests $(\mathrm{m}=30.9259$ in pretest, and $\mathrm{m}=31.6481$ in posttest; $\mathrm{t}=-.776$, $\mathrm{P}>0.05)$.

Table 10. Comparison of the results from the pretest and the posttest of EG

\begin{tabular}{lll}
\hline Group & Experimental Group & \\
\hline Test & pretest & posttest \\
Number & 56 & 56 \\
Mean & 31.7321 & 44.5714 \\
Std. Deviation & 5.55183 & 5.63385 \\
T-test & -12.275 & \\
Sig.(2-tailed) & .000 & \\
& $\mathrm{P}<0.05$ & \\
\hline
\end{tabular}

Table 11. Comparison of the results from the pretest and the posttest of CG

\begin{tabular}{lll}
\hline Group & Control Group & \\
\hline Test & pretest & posttest \\
Number & 54 & 54 \\
Mean & 30.9259 & 31.6481 \\
Std. Deviation & 5.28741 & 4.81020 \\
T-test & -.776 & \\
Sig.(2-tailed) & .441 & \\
& $\mathrm{P}>0.05$ & \\
\hline
\end{tabular}

Therefore, as to the third research question, the answer is positive. Length Approach is quite effective in cultivating learners' vocabulary productive competence.

\subsection{Results from the Final Examination in the Second Term}

Table 12. Comparison of the results in the final examination between the two groups

\begin{tabular}{llllll}
\hline Group & $\mathrm{N}$ & $\mathrm{M}$ & $\mathrm{SD}$ & $\mathrm{T}$ & Sig.(2-tailed) \\
\hline EG & 56 & 71.6429 & 10.02529 & \multirow{2}{*}{3.405} & .001 \\
CG & 54 & 64.8796 & 10.77643 & & $\mathrm{P}<0.05$ \\
\hline
\end{tabular}

Note. $\mathrm{N}$ refers to the number of the participants.

In this section, comparisons of the participants' performance in the final examination which was carried out after the experimental teaching are analyzed. In terms of their comprehensive English proficiency, as Table 12 shows, the learners' performance of the experimental group differed significantly from that of the control group. Both the mean scores $(E G: m=71.6429 ; C G m=64.8796)$ and the $t$-value $(t=3.405)$ indicate that participants of the experimental group performed much better than those of the control group. 
Table 13. Comparison of the results from the final examinations in the first term and second term for the EG

\begin{tabular}{lll}
\hline Group & Experimental Group & \\
\hline Term & 1 & 2 \\
Number & 56 & 56 \\
Mean & 67.4821 & 71.6429 \\
Std. Deviation & 10.56537 & 10.02529 \\
$\mathrm{~T}$ & -7.996 & \\
Sig.(2-tailed) & .000 & \\
& $\mathrm{P}<0.05$ & \\
\hline
\end{tabular}

Table 14. Comparison of the results from the final examinations in the first term and second term for the CG

\begin{tabular}{lll}
\hline Group & Control Group & \\
\hline Term & 1 & 2 \\
Number & 54 & 54 \\
Mean & 63.8426 & 64.8796 \\
Std. Deviation & 11.68567 & 10.77643 \\
$\mathrm{~T}$ & -1.892 & \\
Sig.(2-tailed) & .064 & \\
& $\mathrm{P}>0.05$ & \\
\hline
\end{tabular}

From Table 13, we can see that the experimental group has made great progress in terms of their comprehensive English proficiency. The score mean $(\mathrm{m}=71.6429)$ in the second term examination is much higher than that of the first term $(\mathrm{m}=67.4821)$. The difference is quite obvious $(\mathrm{P}<0.05)$. While, as to the control group (See Table 14), although the mean $(\mathrm{m}=64.8796)$ in the second term is higher than that in the first term $(\mathrm{m}=63.8426)$, there is no significant difference $(\mathrm{P}>0.05)$.

\subsection{Results from the Questionnaire}

A questionnaire is conducted among the experimental group with a view to exploring all the participants' personal feelings about the questions in which the researcher shows interest. Most of the items are adapted according to those made by Wang Chuming (2005). The questionnaire is distributed to the participants in class and is collected fifteen minutes later. For each item, the means of the participants' marking are figured out. And Table 15 reports the specific results of the means.

Table 15. Means of the items in questionnaire

\begin{tabular}{ll}
\hline Item & Mean \\
\hline 1. Length Approach is more helpful for me to organize and convey my ideas. & 4.05 \\
2. Length Approach makes me more aware of building vocabulary size. & 3.88 \\
3. Length Approach encourages me to accumulate more expressions during the process of English learning. & 4.13 \\
4. Length Approach helps to raise my consciousness of using new words and expressions in writing. & 4.16 \\
5. Length Approach changes my vocabulary learning methods from mechanical rotting to flexible use. & 3.70 \\
6. Length Approach makes it much easier for me to remember the new words and expressions. & 4.07 \\
7. Length Approach motivates me to use more English expressions. & 4.09 \\
8. Length Approach can facilitate my productive ability in vocabulary learning. & 4.11 \\
9. I am able to use various expressions to convey myself in a flexible way in writing long compositions. & 3.93 \\
10. I feel I can express myself better through writing long compositions. & 3.59 \\
11. It becomes less difficult for me to write in English after the practice of Length Approach. & 3.50 \\
12. Length Approach is more helpful to enhance my comprehensive proficiency of English. & 4.09 \\
13. Length Approach helps strengthen my confidence in English learning. & 3.32 \\
14. Length Approach is very effective to foster my English vocabulary learning. & 4.11 \\
\hline
\end{tabular}

The figures in Table 15 show clearly the participants' attitude towards different items related to Length Approach.

To be specific, Item 1, Item 10 and Item 11 are designed to help find out whether Length Approach enables 
learners to express themselves freely in a better way. The means $(\mathrm{m}=4.05$ for item $1 ; \mathrm{m}=3.59$ for item 10 and $\mathrm{m}=3.50$ for item 11) of these three items tell that the answer is definitely positive.

As to Item 10, there are altogether more than $62 \%$ participants agree that "I feel I can express myself better through writing long compositions".

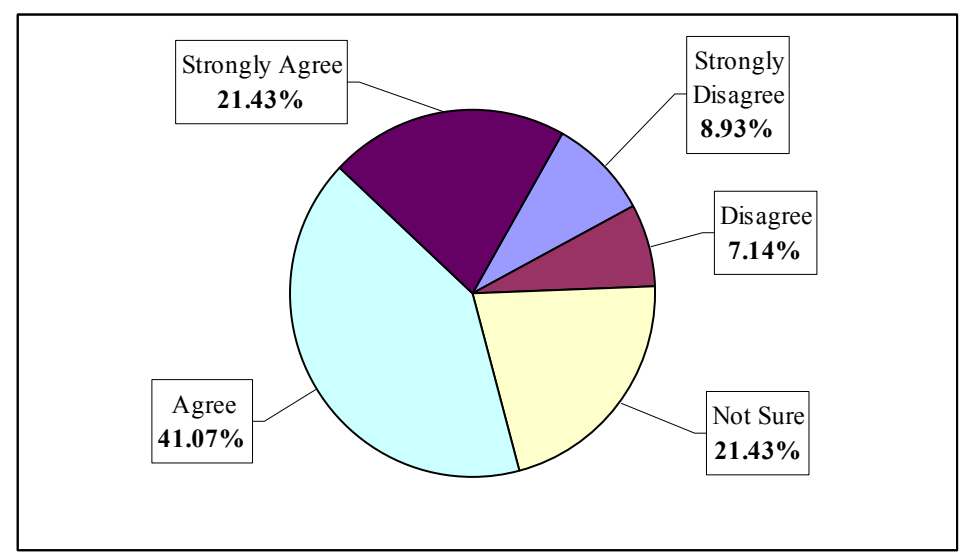

Figure 1. Percentages of item 10

The key part of this survey covers from Item 2 to Item 9 and Item 14, a conclusive one. First, Item 2, 3, 4, 5 and Item 7 mainly deal with the effects of Length Approach on raising learners' awareness of using new words from different perspectives. The means of these are all above the dividing value 3 , and those of Item 3 , Item 4 and Item 7 are higher than $4(\mathrm{~m}=4.13$ for item $3 ; \mathrm{m}=4.16$ for item 4 and $\mathrm{m}=4.09$ for item 7$)$. This means that Length Approach plays an effective role in raising learners' awareness to shift their attention to practical use of English vocabulary. Besides, Item 6 is concerned with the effect of Length Approach on vocabulary memory. The mean is as high as 4.07, which indicates that it is helpful to remember words through writing long compositions. And furthermore Item 8 and Item 9 are used to explore the effects of Length Approach on learners' vocabulary productive ability. The high means of these two items $(m=4.11$ for item $8 ; m=3.93$ for item 9$)$ reflect the positive role of Length Approach in enhancing learners' productive competence. As to Item 14, it is designed as a conclusive remark to investigate the role that writing long compositions plays in facilitating the improvement of vocabulary ability. According to the mean of it $(\mathrm{m}=4.11)$, conclusion can be drawn: the participants have approved of the positive effects of Length Approach on their English vocabulary learning.

For Item 4 "Length Approach helps to raise my consciousness of using new words and expressions in writing", we can see that from the flowing figure (Figure 2) there are up to $42.86 \%$ participants show "Agree", and $39.29 \%$ "Strongly Agree". This indicates that writing long compositions is fairly effective to arouse learners' awareness of using new words and expressions.

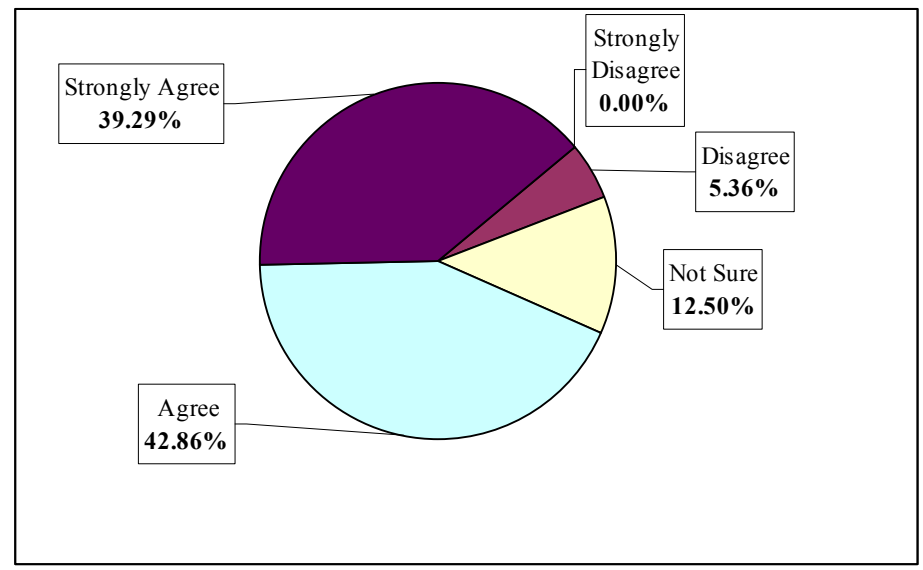

Figure 2. Percentages of item 4 
Meanwhile, in terms of the effects of Length Approach on learners' vocabulary productive competence, more than $85 \%$ participants agree that "Length Approach can facilitate my productive ability in vocabulary learning". (See Figure 3)

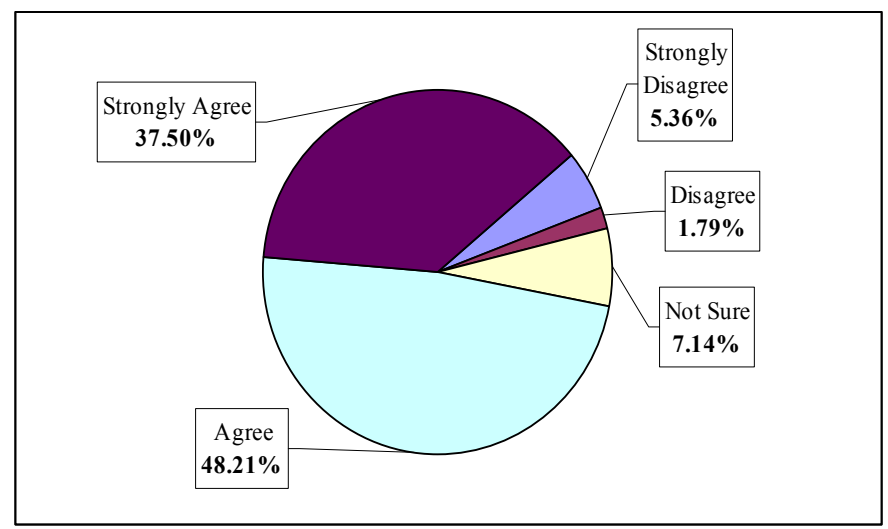

Figure 3. Percentages of item 8

Item 12 is employed to probe into the role of Length Approach in the development of the comprehensive English proficiency. The mean is 4.09 , which shows that writing long compositions can positively enhance learners' comprehensive proficiency. Meanwhile, as far as "Length Approach is more helpful to enhance my comprehensive proficiency of English" is concerned, there are up to $29.82 \%$ and $50.87 \%$ participants show "Strongly Agree" and "Agree", respectively.

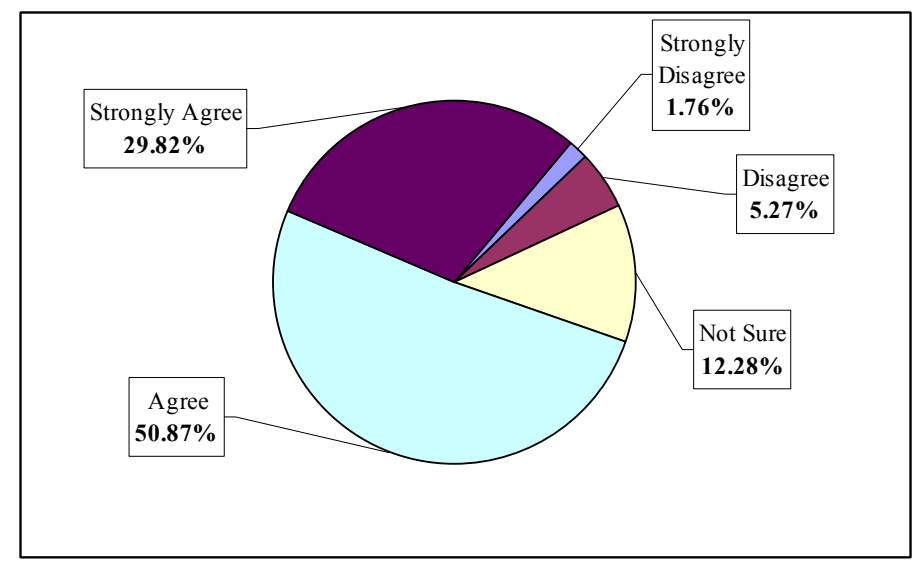

Figure 4. Percentages of item 12

Finally, Item 13 is mainly about the effect of Length Approach on participants' affective factor. The mean is not very high $(\mathrm{m}=3.32)$. But it is also more than 3 point. Generally speaking, writing long compositions has contributed significantly to the building-up of learners' self-confidence.

To sum up, all the means of these items are higher than 3, and some of which are higher than 4. These figures reflect that Length Approach is an effective means to raise learners' productive consciousness, to cultivate their vocabulary productive competence and enhance their whole English proficiency.

\subsection{Results from the Interviews}

A semi-structured interview procedure is employed to investigate the participants' subjective attitude to the effects of Length Approach on their vocabulary learning.

Among six interviewees, each receives an individual interview with the researcher. They are interviewed to offer a further understanding of the effects of Length Approach. The researcher pays careful attention to the interviewees' description. 
The findings in this part demonstrate that Length Approach contributes a lot to learners' vocabulary learning. They tend to pay more attention to the use of the words rather than rote learning. One of the interviewees put it in this way:

During the first term of my college life, I felt much pressure in college English learning. There were so many new words in each unit for me to remember. I spent most of my time memorizing words according to the word list. Unfortunately, I always cannot find any new words when I want to express myself in English. Writing long compositions really changes my learning method. ...I have been trying to use more new words and expressions in long-composition writing.

Previously, they mistakenly took English vocabulary learning as building vocabulary size, paying less attention to output practice. So, when they were asked to make up a sentence with the words, they felt rather confused.

... when I did the pretest, I felt so frustrated that I even could not make up a simple sentence with the words that I had memorized. Writing long composition helped me realize my inefficient way of vocabulary learning. ... and I feel a sense of achievement when I saw the teacher's positive comment on my writing. I become more confident. I think I've done better in the posttest. Moreover, I think I need to do more reading. I tend to be more aware of some wonderful expressions when I read English articles. And I have prepared a notebook to put them down.

Before the long composition writing practice, a majority of the students did not take writing seriously. Writing was a burden to them. However, Length Approach changed that. We can get evidence from the remarks of another interviewee:

Writing always caused me headaches previously. I felt I had nothing to say. Personally speaking, I thought writing is only a waste of time. I just finished it in a hurry and handed it in. ...Length Approach not only stimulates me to enlarge my vocabulary size, but also encourages me to use as more new expressions as possible. Seeing there are so many beautiful expressions underlined by the teacher, I feel proud of myself. I don't regard writing as something boring any more. To tell the truth, Length Approach is really very helpful to my vocabulary learning.

Length Approach not only serves to raise learners' consciousness of using English words, but is also of vital significance to develop their initiative in English learning. During the interview, the researcher finds that almost all the 6 interviewees consider vocabulary as the most important element in English learning. And almost all of them confess that they have spent most of their time in vocabulary learning, but the result is anything but fruitful. They say that the biggest problem is that they have difficulty in memorizing new words effectively. When it comes to vocabulary learning, they feel rather confused. Some even have a sense of inferiority just because of their poor English, especially, due to the small vocabulary size. They have no self-confidence.

However, after long-composition writing practice, they begin to be interested in English learning. In particular, they think they have found one effective way of learning English words. In addition, Length Approach helps to arouse their initiative. They realize that they tend to learn much more quickly and better when they try to put the newly learnt words and expressions into use by writing.

And they remark that Length Approach not only helps them recognize the problems existing in their English vocabulary learning but also helps resolve them to a large extent.

\subsection{Discussion}

Based on the above detailed analyses of the data from the tests, questionnaire and interview, a general conclusion can be drawn, that is, Length Approach has positive effects on English vocabulary learning.

According to information processing theory, learning is based on a learner's depth of processing or how in-depth we encode information into long-term memory and therefore how easily we are able to retrieve it (Crail \& Lockhart, 1972). And numerous researches in the L2 field have shown that output activities that involve deep processing can enhance learners' performance in vocabulary learning. One recent study of Professor Wang Chuming(2004)also claims the positive role of writing long composition in L2 vocabulary learning, especially the effect on long-term retention of vocabulary. The present research provides support for the claim from another perspective: writing long composition can not only raise learners' awareness of output but also foster learners' productive competence in their vocabulary learning. The comparison of the results between the traditional approach and Length Approach can contribute to such conclusion that Length Approach exerts beneficial effects on learners' vocabulary productive ability. It has proved that after being taught in the Length Approach, the learners have performed far better than they did before. In addition, long-composition writing tasks after class could arouse learners' awareness of autonomous learning of vocabulary. As a result, the learners of the experimental group would be more sensitive of the usage of newly learnt words than the learners of the control 
group. They tend to do more reading to enlarge their vocabulary size, to pay more attention to beautiful expressions when reading English passages and to using more new words and expressions in their writing consciously. Gradually, they will develop the habit of using newly learned words in new contexts.

Furthermore, this study finds that Length Approach is also feasible among non-English majors. Previously, there were misconceptions existing among non-English majors as to English learning. The majority of them held that they could learn English well as long as they have a large vocabulary. They devoted most of their time to memorizing words by rotting memorization, paying little attention to generative use. Therefore, they were always faced with the dilemma of finding no words to express themselves effectively. And sometimes, they even complained of their low efficiency in vocabulary learning. Unfortunately, they fail to reason out the cause which lies in the lack of comprehensible output practice. The information from the interviewees indicates that Length Approach really helped them a lot from different aspects. Their ineffective vocabulary learning method, the previously negative attitude towards writing, and the productive ability have all been improved to a large extent. Moreover, their interest and motivation as well as their metacognitive awareness were stimulated to some degree.

To conclude, the analyses of the data from the tests and questionnaire, along with the information from the interview all serve well to answer the research questions.

1) Learners' productive competence of vocabulary doesn't develop correspondingly with their vocabulary size.

2) Length Approach is helpful to raise learners' consciousness of using new words and expressions.

3) Length Approach is an effective means to foster learners' productive competence in L2 vocabulary learning.

4) Length Approach plays a positive role in enhancing learners' comprehensive English proficiency in the process of second language acquisition.

\section{Conclusion}

The study was conducted with a view to investigating the effects of Length Approach on L2 vocabulary learning. The major findings of the research are presented as follows:

With regard to college English vocabulary learning, learners' productive ability lags far behind their receptive ability. That is, learners' capability of using words in communication does not develop correspondingly with their vocabulary size. Learners tend to learn English words by means of studying the word list, which may be very dangerous, since what it displays is just pronunciation, word class, target-language equivalents, derivatives and occasionally one or two examples. This information in isolation, however, is less likely to contribute to students' productive ability. As a result, learners fail to make up a sentence appropriately with the newly learnt words, although they have a large vocabulary size.

Long composition writing task leads learners to become more aware of the new expressions or lexical phrases which can help enrich the content of their writing. The requirement of Length Approach is helpful to arouse learners' consciousness to accumulate new words and expressions and then use them in their writing.

Length Approach is an effective approach to promote learners' language proficiency, especially their vocabulary productive competence. The data from the experiment provides supporting evidence to prove that exposure to meaningful comprehensible output practice enables learners to improve a lot in terms of language productive proficiency.

The information from both the questionnaire and interview demonstrates that Length Approach plays a positive role in building-up students' confidence, developing their initiatives, arousing their interest and motivating them to use more new words and expressions in writing practice, and enhancing their ability in English vocabulary learning.

Length Approach, through awakening a producing desire and awareness in learners, promotes the transition from input to intake by timely practice of long composition writing.

\section{Acknowledgements}

This research was supported by the Fundamental Research Funds for the Central Universities of China (2014ZX12).

\section{References}

Candlin, C. N. (1988). Vocabulary and Language Teaching. London: Longman.

Crail, F. I. M., \& Lockart, R. S. (1972). Levels of processing: A framework for memory research. Journal of 
Verbal Learning and Verbal Behavior, (11), 671-684. http://dx.doi.org.10.1016/S0022-5371(72)80001-X

Fang, L. L. (2004). A Study of Length Approach in College English Teaching. Foreign Language World, (3), $40-45$.

Gass, S. M., \& Selinker. (1994). Second Language Acquisition: An Introductory Course. Amsterdam: John Benjamins.

He, Z. R. (2004). On the Reversed Thinking in Foreign Language Teaching. Foreign Language World, (6), 2-7.

Levine, A., \& Reves, T. (1990). Does the Method of Vocabulary Presentation Make a Difference? TESL Canada Journal, 8(1), 37-51.

McCarthy, M. J. (1990). Vocabulary. Oxford: Oxford University Press.

Nation, I. S. P. (1990). Teaching and Learning Vocabulary. New York: Newbury House.

Qian, G. L. (2004). A Big Change in Error Correction-What Length Approach Found Out. Beijing: Science Press.

Qin, X. B. (2004). A New Approach to Improve English Learning Efficiency. Beijing: Science Press.

Rivers, W. (1983). Communicating Naturally in a Second Language. Cambridge: Cambridge University Press.

Vermeer, A. (1992). Exploring the second language learner lexicon. In L. Verhoeven \& L. H. A. L. de Long (Eds.), The Construct of Language Proficiency (pp. 147-162). Amsterdam: John Benjamins.

Wang, C. M. (2004). Learning Vocabulary by Writing. Beijing: Science Press.

Wang, C. M. et al. (2000). Learning by Writing. Foreign language Teaching and Research, (3), 207-212.

Wang, L. F. (2004). The Validation of Length Approach: A Report on Long Essay Writing. Beijing: Science Press.

Wang, Q., \& Deng, D. (2012). A Study of Length Approach in College English Writing Assessment. Foreign Language World, (5), 17-23.

Wesche, M., \& Paribakht, T. S. (1994). Enhancing vocabulary acquisition through reading: A hierarchy of text-related exercise types. Paper Presented at the American Association of Applied Linguistics.

Wilkins, D. A. (1972). Linguistics in Language Teaching. Edward Arnold Ltd.

Wu, F. (2005). Comprehensible Output and Language Learning Efficiency-An Empirical Study on Length Approach. Foreign Language Education, (1), 44-48.

Zhong, S. (2004). The Methodology of Length Approach from the Perspective of Constructivism. Foreign Language World, (3), 46-50.

\section{Copyrights}

Copyright for this article is retained by the author(s), with first publication rights granted to the journal.

This is an open-access article distributed under the terms and conditions of the Creative Commons Attribution license (http://creativecommons.org/licenses/by/3.0/). 